\title{
Collaboration in the Cloud for Online Learning Environments: An Experience Applied to Laboratories
}

\author{
Washington Luna ${ }^{1}$, José Luis Castillo Sequera ${ }^{2}$ \\ ${ }^{1}$ Polytechnic School of Chimborazo, Riobamba, Ecuador \\ ${ }^{2}$ Alcala University, Madrid, Spain \\ Email: wluna@espoch.edu.ec, jluis.castillo@uah.es
}

Received 30 May 2015; accepted 2 August 2015; published 5 August 2015

Copyright (C) 2015 by authors and Scientific Research Publishing Inc.

This work is licensed under the Creative Commons Attribution International License (CC BY). http://creativecommons.org/licenses/by/4.0/

(c) (i) Open Access

\begin{abstract}
Nowadays, Cloud computing has become essential support for online education. Growth and interest in the massive open online courses (MOOCs) hosted on cloud, as well as the large number of students with own device (BYOD) set a favorable scenario for a new model of cooperation and interaction for online education. In this paper we present the results of collaborative work in the cloud, using Google Apps services and MOOCs, in conducting laboratory reports for the subjects of chemistry, and based on this experience we propose an architecture for platforms e-learning and mechanisms for collaborative work in cloud applied to the laboratories.
\end{abstract}

\section{Keywords}

Collaboration, Cloud, Massive Open Online Courses, Distance Education, Bring Your Own Device

\section{Introduction}

Today's students are immersed in technology and see it as an essential tool for learning because they use a variety of strategies to collect and sort data, to communicate and collaborate with their peers. According to (Conole \& Unido, 2013), effective learning is that which:

- Encourages reflection;

- Allows dialogue;

- Promotes collaboration;

- Applies the theory learned into practice;

- Creates a community of peers; 
- Allows creativity;

- Motivates students.

Technology offers many ways in which these features can be developed through interaction, using multimedia, and communication and collaboration with colleagues. Therefore, as a result, technologies can be used to promote various pedagogical approaches and improve learning.

The new models of e-learning can draw on the experience of existing technologies like MOOCs and cloud computing to adopt a forward-thinking approach, in order to employ a new implantation strategy, publication and platform use, at the service of education.

Online collaboration allows the collection of data for the comparison, discussion, analysis and feedback of knowledge among students, being an effective way to obtain experimental data that demonstrates the power of technology in group projects which generate reports of its practices.

Furthermore, laboratory practices in chemistry for teachers have difficulties with the individualized follow-up of a large group of students, adding to it, other relatively influential factors as: the short time for the realization of the practice, reactants, equipment, materials and required technical information. It is then pertinent that teachers provide a collaborative and guided direction to students at every stage of the of the laboratory procedures, especially in preparing the report of the practice, using IT tools to monitor and assess the work of students team. As mentioned (Barkley, 2007) "collaborative learning occurs when students and teachers work together to create knowledge... It is pedagogy which imparts the basis that people create meaning together and that the process enriches and makes them grow".

The experiments and the corresponding reports involve the participation of all members of the practice group and the faculty, usually being evaluated with an oral or written defense.

The completion of a report, in a way, is an activity for students to recapitulate the technical principles of a theme or scientific phenomenon of a chemical nature. It can also be considered an activity that aims to balance the drawbacks of logistic nature so that everyone may be involved in chemical lab practices. From our state of the art study, we have not found MOOCs platforms that promote the application of collaborative learning techniques in the development of their respective laboratories and reports.

The computer resource most used in the development of experiments is the LMS, so for example, at the Sciences Faculty of the Polytechnic School of Chimborazo (ESPOCH), the Moodle platform is used as a virtual classroom to support the on-campus modality.

The collaborative environment for teaching and learning in teacher-student relationship is useful for the development of individual and group skills, starting from discussions between students and the teacher's moderation, promoting the growth of the group.

Often, at the Sciences Faculty, cloud applications like: Google Apps, MOOCs, BYOD, among others, have not been adequately used, despite its versatility objectives for online collaboration and the publishing of documents for both teacher and student, despite having a lot of usability and accessibility, being very friendly and free. Therefore, these applications are viewed as very helpful for the activities of the teacher, student and professional, by presenting interrelation media synchronized in the cloud, and the possibility of maintaining work documentation orderly, by grouping and categorizing it.

Thus, it allows teachers and students to work in the cloud, in a grouped and collaborative way, using applications such as Google, and its medium may be any computer anywhere and anytime.

The research's aim is to comparatively evaluate the improvement in the level of collaborative work between the traditional mode and the mode using cloud tools, integrated Google Apps services and MOOCs in reporting chemistry laboratory experiments.

This article is organized as follows: Section 2 exposes the state of the art technologies and implantations of laboratories such as cloud computing, MOOCs and BYOD. In Section 3 we present a proposal to improve the architecture and mechanism used for collaborative work with MOOCs. Section 4 reports our case study and its application in the Faculty of Sciences of the Polytechnic School of Chimborazo, on collaborative work in conducting chemical laboratory experiments. Section 5 describes and analyzes the results of the experience, and finally Section 6 proposes the conclusions.

\section{Review of Literature}

A review of the literature, we can establish that the cloud computing, the MOOCs and the proliferation of computers and devices owned by students (BYOD) (Sayler, Grunwald, Black, \& White, 2014), are helping online 
education or e-learning, however most implementations do not have tools to promote the use of laboratories for experiments that the vast majority of technical subject so require. The implantations of practical laboratories have limitations such as weak collaboration and sharing of resources, difficulty of reconfiguration and adaptation, restricted periods of use and access to a limited number of students (Xu, Huang, \& Tsai, 2014).

\subsection{Cloud Computing}

In education, cloud computing has been identified as a key trend (Johnson, Adams, \& Cummins, 2012) that allows access to online services anywhere with improved scalability and availability that is cost-effective (Mircea \& Andreescu, 2011). These are desirable properties to provide e-learning services, especially in scenarios of intensive computing services and virtual worlds, simulations, streaming video, or those being offered on a large scale as in MOOCs (Massive Open Online Courses) (Moltó \& Caballer, 2013).

The cloud provides students and teachers tools to deploy computing resources on demand for the development of classes and laboratories according to their needs. For example, teachers can create virtual computers on demand with pre-installed software quickly-to-implement laboratory (Bandi, Nori, Choppella, \& Kode, 2011). Some schools are already using cloud computing to outsource email, collaboration tools, and data storage or to house Virtual Learning Environments (VLE) (Unesco, 2010). Another strong point of cloud computing is the ubiquity with advanced collaboration tools which can produce new scenarios to create innovative forms of education.

The paradigm of cloud computing provides a set of virtual resources (hardware, development platforms or services) available on the network. These computational capabilities can be quickly delivered and removed to scale quickly according to demand.

Cloud computing services usually fall into three main types: At the lowest level of abstraction we can find Infrastructure as a Service (IaaS) (Bhardwaj, Jain, \& Jain, 2010) which provides consumer processing, storage, networks, and other computer resources. An example of IaaS is Amazon EC2 which provides virtual machines on demand. Education institutions can use Eucalyptus and OpenStack to build their own infrastructure. The next level, Platform as a Service (PaaS), usually built on IaaS which allows the user to deploy cloud infrastructure applications through programmatically at supported runtime environments. Examples of PaaS are Google App Engine and Microsoft Windows Azure. Finally, the next level is Softtware as a Service (SaaS), currently being the best known model, consisting of applications offered by the provider through the network, instead of being executed in the user's computer. Examples of SaaS are Google Docs, Salesforce or Dropbox.

In reviewing the state of the art of work on this subject, we found isolated efforts of several universities in the use or implementation of technological infrastructure. The swift arrangement and release of resources on demand offered by the cloud allows teachers to create environments as virtual desktops to access virtual machines and laboratories preconfigured and up development environments that can be replicated or reused as often as necessary (Burd, Luo, \& Seazzu, 2013; Vaquero, 2011), generating less management overhead in the shortterm.

In (Chine, 2010), the author's present elastic-R, a preconfigured VM with mathematical and statistical tools that help students in the analysis of laboratory data to generate reports.

The Laboratory of Molecular Nanotechnology at the University of Alicante has developed an educational project on nanotechnology in Spain, NanoMOOC, which can be displayed on mobile devices, tablets and computers (NanoMOOC, 2014). NanoMOOC has been designed using the Google Course Builder platform.

In (Sinex \& Chambers, 2013) the experience of collaborative work between groups is described, with the collecting data from a chemistry lab using Google Drive, and then projecting the data to the entire class for analysis and interpretation aided by an Excel spreadsheet. Furthermore, the results of a survey of participants are presented, though their participation is not evaluated, through performance and exposure of the lab report.

In the same line of the previous article, (Abrams, 2012) Dropbox is used in an LMS for teaching laboratories, in this way, an easy way to collect large amounts of data for later analysis with minimal effort reported.

Therefore, computer science teachers can pre-configure and assigning resources to start from scratch. For example, there is a contribution, proposed in (Rajaei \& Aldakheel, 2012) using virtual databases created in Microsoft Windows Azure and AWS VMs to learn the functioning of operating systems.

It is noteworthy to mention work (Xu, Huang, \& Tsai, 2012), which describes a remote laboratory V-lab, where teachers can configure virtual machines for students to access remotely for network practices. 
The Hochschule Furtwangen University (HFU), implemented a private cloud platform, using the three service models, IaaS, PaaS and SaaS, called CloudIA, which serves their students and the general public with e-Learning and collaboration services. Furthermore, with CloudIA, students can create and reserve virtual machines on demand for their practices. By default only three virtual machines with 1 GB of RAM are handed per student with up to 100 hours per semester (Doelitzscher, Sulistio, Reich, Kuijs, \& Wolf, 2011). In this line of work, (Anton, Anton, \& Borangiu, 2012) shows the case of a private cloud shared by four universities that allow the provision of virtual machines with preconfigured images created on demand by computer science students. In a different contribution, StarHPC developed by the Massachusetts Institute of Technology (MIT), proposed virtual machines that can be reused among students in a parallel programming course (Ivica, Riley, \& Shubert, 2009).

Furthermore, because the cloud not only allows virtualized machines, but network resources, professionals have the flexibility to design computing clusters and networks that are fully adapted to the requirements of the task or the laboratory. For example, in (Yan, 2011) a laboratory of computer networks in a private cloud where students can configure servers, firewalls and switch is proposed.

Other networks laboratories built in a flexible manner with cloud tools are described in (Mikroyannidis, Rizzardini, Schmitz, \& Fraunhofer FIT, 2012) where virtual clusters are configured based on CloudStack for parallel programming tasks.

To meet performance and price levels of the cloud you can opt for hosting virtual machines on multiple clouds. In (Woo \& Mirkovic, 2014) an increase in performance and cost reduction in the allocation of resources in several clouds, compared to allotment of resources in a single cloud for a variety of realistic scenarios is reported.

In (Li, Peng, Zhang, Han, \& Yuan, 2011) a design and mechanism for collaborative work based on cloud platforms and LMS for teaching classes is proposed and it is established that for efficiency, groups of 3 - 6 students should be formed and a leader appointed for each group which will interact with the teacher and the rest of the group. The architecture has four layers based on Web services and the mechanism of usage is based on the realization of projects based on discussion and collaboration with members of each group. Despite being an interesting project, it has constraints on collaboration and scalability by not including existing technology that we already have at present and which have been accepted by students for its ease of use, such is the case of social networks including MOOCs.

\subsection{BYOD (Bring Your-Own-Device)}

The cloud can help overcome current limitations in mobile learning in relation to the limited processing and storage capacity of current devices, primarily through the provision of adequate computing resources and scalability (Moltó \& Caballer, 2013). Thus, applications can run on mobile devices while the heavier computing tasks such as virtual machines, are executed in the cloud (Gajar, Ghosh, \& Rai, 2013). Students can also use their mobile phones to access, share and synchronize learning content stored in the cloud with the appropriate quality of service (QoS) anytime and anywhere (Norris \& Soloway, 2011).

In this scenario, where education is facing a paradigm shift in the ownership and use of computing hardware, the institution's computer lab are no longer the main site for practices. Students increasingly use their own computers do to homework. This scenario creates a challenge, now they have to endure a wide range of heterogeneous hardware without strict controls on its use.

In computing, the problem is compounded by the prevalence of applications and different operating systems, which poses a significant challenge. To address this issue, in article (Sayler et al., 2014), the authors propose to use what is known as "Bring Your Own Device” (Bring Your-Own-Device BYOD), building and deploying virtualization software to develop environments for the dictation of courses of computer science. This system has been deployed and tested for two years and is still used actively. It has been reported that the system supports multiple classes with hundreds of students with limited IT support staff. In the study, the design and management of the system is described, and the experience with students is presented, demonstrating its effectiveness for the BYOD challenge, with good cost to efficiency relation and ease of use. For this, he used Oracle VirtualBox as hypervisor, and on top of this, an image of virtual machine based on Ubuntu 12.04.3 was created with software such as ruby, scala, python, and gcc. The image distribution of the VM was performed using the open virtualization format (.ova), which allows students to import and install (assuming VirtualBox is already installed). One of the fundamental challenges behind the use of a single virtual machine is to manage the specif- 
ic requirements of each class. For this purpose, a system for software management for several machines with the mentioned Debian management package utilities.

\subsection{MO0Cs (Massive Open Online Course)}

With the globalization of education and limited budgets, the MOOCs are causing changes in education and learning, creating a new model of open and mass education (Yuan \& Powell, 2013).

Articles about MOOCs have diverse and extreme views from those who think they are a threat to the university to those who assume they are a fad (Cusumano, 2014; Daradoumis, Bassi, Xhafa, \& Caballé, 2013).

Much research on MOOCs, show the high desertion from the MOOCs attributed to factors such as lack of motivation, recognition for educational credits from universities, lack of quality, theoretical teaching without laboratory practice (Hew \& Cheung, 2014). From the point of view of the creators, obstacles for publication like the high investment of time and resources without clear business model are cited. The monopoly of platforms is also cited by elite universities (Hew \& Cheung, 2014).

In a recent (Margaryan, Bianco, \& Littlejohn, 2015) study, presents an analysis of the quality of the instructional design of 76 massive open online courses (MOOCs) selected randomly, through a survey, were evaluated and compared and found to be that most MOOCs have low quality, and 68 of the 76 MOOCs have collaborative activities.

On the other hand, in several studies have demonstrated a significant contribution that MOOCs have given to education, with excellent results, as in the case of a study on entrepreneurship based on MOOCs that highlights the high rate of retention and collaboration obtained (Al-Atabi \& Deboer, 2014).

Likewise (Pedreño et al., 2013) presented specialized tools to learn how to operate in a collaborative work platform called UniMOOC which has an alumni network that can be interconnected with each other based on their preferences. This is intended to exploit the collaborative work as virtual networking, connectivity and promoting the formation of professional networks.

\section{Proposal}

Based on our state of the art study, particularly in the proposal of Geoffrey C. Fox in his article (Fox, 2013) and also in architecture and mechanism proposed in ( $\mathrm{Li}$ et al., 2011) we suggest an architecture for online education environments and mechanism of collaborative work for the realization of laboratories and their respective report, using virtualization technologies, cloud computing, MOOCs and BYOD. The proposed architecture has four layers, as shown in Figure 1.

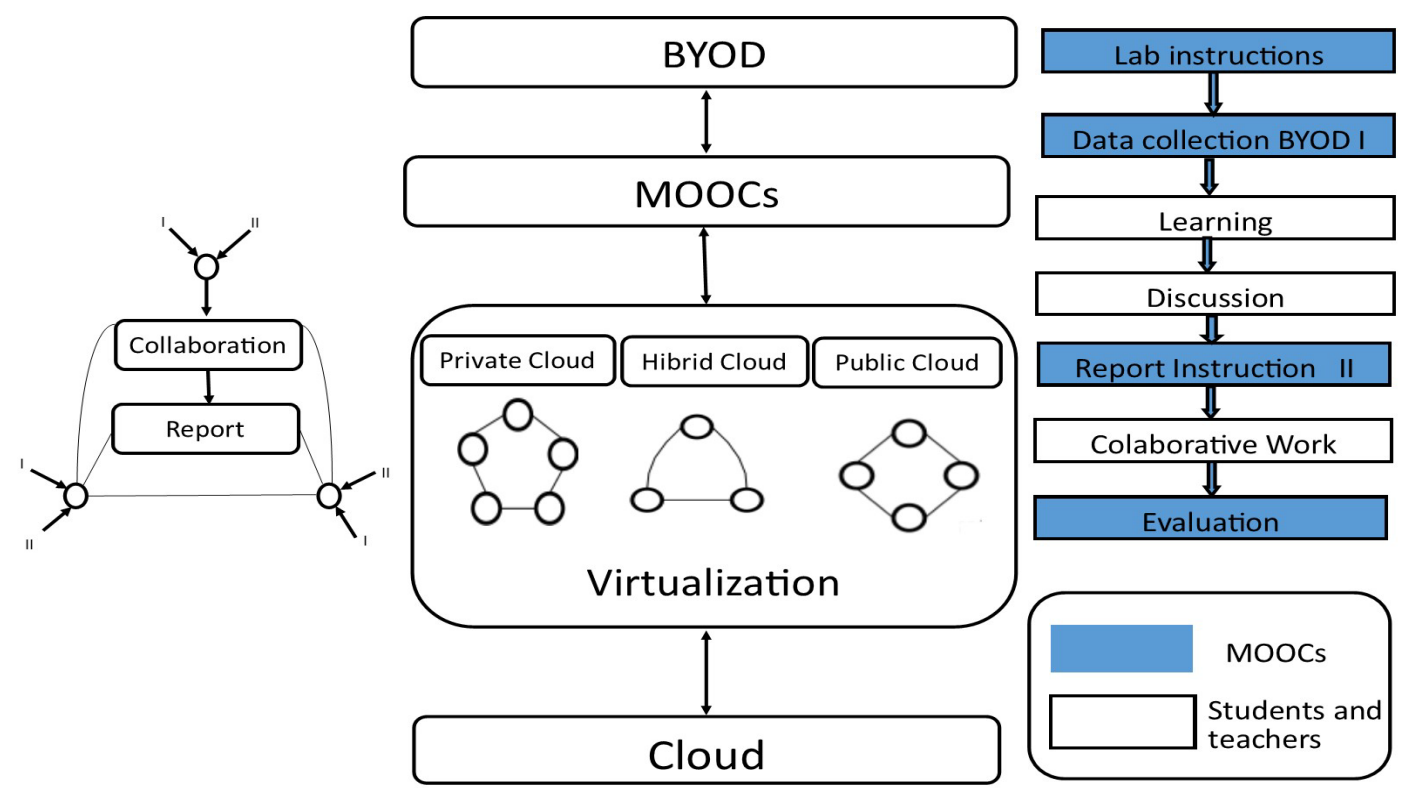

Figure 1. Architecture and mechanism for collaborative work in conducting laboratory reports. 
- The first layer corresponds to the cloud with all the services it can provide as Infrastructure, Platform and Software, which must be implemented depending on the institution with a model of public or private cloud or a combination of these models leading to a hybridized cloud. This layer provides the basis for the next layer of virtualization.

- The virtualization layer will house a repository of virtual machines with suitable software for performing labs and their reports. The VM can be selected by groups of students who undertake collaborative work to analyze the data collected in the fourth layer The preinstalled software on VM facilitates data analysis can be $\mathrm{R}$ or SPSS and spreadsheets like Excel. After analyzing the data with the right tools, students and teachers discuss and collaborate using social networking interface from the MOOCs.

- The third layer corresponds to the MOOCs. The same which presents all the interface containing the structure of the course consisting of a syllabus, theoretical content, demonstration videos, links to access virtual machining and diagnostic tests. The contents and instructions for each laboratory will be determined according to the group.

- The advantage of using MOOCs, is the possibility to attend a large number of students. The MOOCs must submit their content based on principles of instructional design (Merrill, 2013) and using the right technology for each task, as suggested by the model TPACK (technological pedagogical content knowledge) (Koh \& Chai, 2014).

- The fourth layer corresponds to BYOD, where each student can work and collect data from their own devices through a direct connection with the third layer corresponding to the MOOCs.

\section{Practical Case}

The research was conducted by the Faculty of the Polytechnic School of Chimborazo. We worked with all of the relevant population of students of the subjects of Biochemistry I, Food Chemistry and Biochemistry, schools of Biochemistry and Pharmacy and Chemical Engineering

To assess the improvement in collaborative work, cloud hosted virtual machines were used for statistical and spreadsheet software, the same which could be accessed from a MOOCs that had links with Google apps. A lab was performed on each subject, collecting data and analyzing them by groups; a report was generated with the results. Furthermore, the same work was done in the traditional manner.

The mechanism to start the process follows the steps shown in Figure 2.

- Phase I. The teacher determined the laboratory, and explained its purpose and procedure through MOOCs platform. The students took over and proceeded to collect field data through their BYOD devices and fed the electronic sheet in the cloud.

- Phase II. Then the students moved forward analyzing the data using the preinstalled software on virtual machines through discussion among group participants. In Phase II the teacher gives instructions to generate the report through MOOCs and students, through collaborative work, generate a group report. The reports are evaluated by the teachers both in quality, participation and progress of each group.

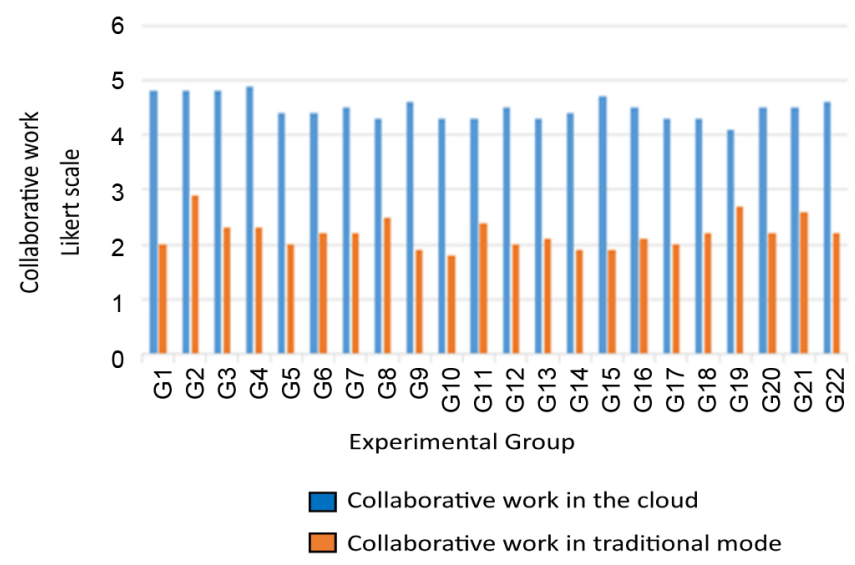

Figure 2. Comparison between collaborative work in traditional model and cloud model. 
Two identical surveys for each student with 20 indicators was used for the assessment of improved collaborative work to assess the effect of using the tools from the traditional way in the collaborative activity of the preparation of the practice report. The surveys have a common form for each of the modalities compared, each indicator will be assessed according to the scale of Likert (strongly disagree SD, disagree D, neither agree nor disagree $\mathrm{N} \mathrm{A} / \mathrm{D}$, agree $\mathrm{A}$, strongly agree $\mathrm{SA}$ ), later this appreciation will be converted by the teacher to their numeric value corresponding to 1 - 5 .

Indicators 19 and 20 relating to the quality and use of knowledge in each type of work are not answered by the students, they are assigned by the teacher in the Likert scale; once processed in groups in their records, the collaborative work using cloud tools and when the traditional mode in the routine teaching process of the academic period in which the experiment is applied, the resulting process is as follows.

\subsection{Quality Rating}

In the modality using cloud tools, the quality of the report is reviewed in groups of 5 points, with the average obtained between the elaborated reports and uploaded to Google Drive on the date requested by the teacher and the value of collaborative work undertaken jointly with the teacher on the date convened. The obtained value over 5 translates to the Likert scale.

In the traditional way of preparing the report, the quality is assessed on 5 points to qualify the written report delivered in a folder by the laboratory group.

The values of 5 qualities obtained in the two modalities are translated into the corresponding Likert statement (SD, D, N A/D, A, SA) and teachers jot-in the results for each survey that polls remain complete in 20 indicators).

\subsection{Assessment of Use}

In the modality using cloud tools, taking advantage of, or, understanding or thematic understanding is valuated in groups of 5 points. The value is obtained by answering the questionnaire prepared in a form created in Google drive immediately after collaborative work with teachers.

In the traditional way of preparing the report, the achievement is valued in groups of five points in the written defense made on the written report submitted.

The use of 5 values obtained in the two modalities are translated into the corresponding Likert scale and teaching notes in each survey this outcome for her to be complete in 20 indicators.

\subsection{Determination of the Level of Collaborative Work}

Having completed the values of the 20 indicators in the surveys in each mode, the teacher in the same survey translates the assigned affirmation, each to the corresponding value of $1-5$, and proceeds to add the values to 20 to have a value of 100 points will be converted to 5 points. The results of each member and each experimental group are averaged to obtain the average group level of collaborative work in the form of work using Google tools and traditional methods used to prepare the lab report.

\section{Results and Discussion}

The results on the three aspects evaluated and the assessment of collaborative work, the quality of reporting and utilization reflected the qualifications set out below.

\subsection{Assessment of Collaborative Work}

The 22 experimental groups generated values of collaborative work on five points in the two modes that are compared with the preparation of the report of the practice. These are shown in Table 1 and Figure 1.

It can be seen that the experimental groups located on a greater level of collaborative work mode using the cloud tools, where the traditional method has not exceeded the value of 3 in the scale of 5.

In interpreting the results, it appears that the mode that uses cloud tools for collaborative improves by $46 \%$ when compared with the traditional method, this means that cloud tools generate and facilitate the better use of the principles and foundations of a lab (in this case chemistry), would be involved as factors that are beneficial compared to traditional, like: 
Table 1. Comparison of collaborative work on cloud and traditional mode.

\begin{tabular}{cccc}
\hline & & Collaborative work & \\
\cline { 2 - 4 } & Cloud & Traditional model & Improvement \\
\hline Averange & 4.5 & 2.2 & 2.3 \\
Percentage & $90 \%$ & $44 \%$ & $46 \%$ \\
\hline
\end{tabular}

- Cloud tools allow more dynamic group work and demonstrate self-responsibility and motivation for their own and others' learning.

- Considering that geographical separation is no longer an obstacle to work the report in the shared document among all members of the group by including the teacher.

- We welcome the participation of teacher guidance at the moment of structuring the report.

- It is interesting to observe that in drafting the report, to be allowed to perform a recapitulation of practice by reporting the procedure of the same as a video feature that is implemented in the drafting format of the report that enriches learning.

- It is interesting to note the fact that there is a means of immediate feedback that is then used for group work with a teacher's guidance.

\subsection{Quality Report}

The cloud tools improved the quality of the report by $22 \%$ compared to the quality of the report with the traditional mode. See Table 2. What was observed can be attributed to that the drafting format was demanded to apply to each part that integrates a lab practice. Thus, in the mode using cloud tools does not neglect the attention and analysis on each side which are in their objectives, discussion of results and conclusions, for in the traditional way a neglect or disregard of certain targets are observed, certain outcomes are not met and in occasions, conclusions of certain parts are not mentioned.

\subsection{Achievement}

The cloud tools improved for practical achievement use by $40 \%$ over the development generated by the traditional method, see the Table 3.

One interpretation for the results in that in form using cloud tools, these allow to collaboratively work under the guidance of teachers, the fundamental practical theories to build a video of the procedure are summarized, foundations are also recapitulated, and the evaluation of understanding is made at the time of completing the development of collaborative activity among students and faculty tutor. An additional aspect that can be mentioned is that teachers do not have to receive physical documents and grade or evaluate them, certainly because when working in the cloud and online, this prevents and eliminates written documents, while simultaneously obtaining the respective qualification.

For statistical verification of our results, we performed the t-student test for paired means of two samples for the 22 groups that experimented and appreciated the preparation of the report in the two modalities. Being dependent groups was considered a test $t$ for paired samples stockings. A hypothetical difference between the means of zero with a significance level of 0.05 was recorded.

Being a dependent group, a t-test was considered for paired sample measures. A hypothetical difference between mean scores of zero at a 0.05 level of significance is noted.

The research hypothesis raised in this study was: $\mathrm{H}_{1}$ : The value of collaborative work by using the cloud in the reporting of laboratory chemical, significantly exceeds the value of the traditional way of making lab reports. This would be represented as follows:

$$
\mathrm{H}_{1}: \mathrm{m}_{\text {Google apps }} \neq \mathrm{m}_{\text {tradicional }}
$$

According to statics software, the inequality indicates a two-tail graph, where statistic $t=30,901$, is larger than the critical value of $t$ (two-tailed) 2073, this means that the $t$ statistic is outside the area of acceptance of the null hypothesis, therefore $\mathrm{H}_{1}$ accepted. Therefore, this defines that there is a significant difference between the means of cloud mode and traditional mode. 
Table 2. Comparison of quality report on cloud and traditional mode.

\begin{tabular}{cccc}
\hline & & \multicolumn{2}{c}{ Quality report } \\
\cline { 2 - 4 } & Cloud & Traditional model & Improvement \\
\hline Averange & 4.5 & 3.4 & 1.1 \\
Percentage & $90 \%$ & $68 \%$ & $22 \%$ \\
\hline
\end{tabular}

Table 3. Comparison of achievement on cloud and traditional mode.

\begin{tabular}{cccc} 
& & \multicolumn{2}{c}{ Quality report } \\
\cline { 2 - 4 } & Cloud & Traditional model & Improvement \\
\hline Averange & 4.4 & 2.4 & 2.0 \\
Percentage & $88 \%$ & $48 \%$ & $40 \%$ \\
\hline
\end{tabular}

\section{Conclusion}

The new e-learning models should learn from the definite experience of existing technologies as MOOCs, BYOD, and cloud computing to adopt a forward-looking approach to apply a new strategy for implantation, publication and use of platforms to service education.

The alternative seems to be on the implementation of ecosystems that use private clouds with existing equipment in laboratories of universities and can interoperate with public clouds, forming scalable platforms.

The assessment of collaborative work according to the process carried out using cloud tools in the reporting of chemistry labs is $90 \%$, while the traditional mode of development reaches $44 \%$. This means that according to our practical experience, improving collaborative work in implementing reports using cloud tools is $46 \%$ compared to traditional mode. Also, the quality of the reports elaborated under the form using cloud tools shows an improvement of $22 \%$ compared to those made in the traditional way. In addition, the advantage of knowledge in the mode using cloud tool shows an improvement of $40 \%$ compared to that obtained by the traditional method.

Therefore, with the obtained results we can say that optionally cloud tools serve to enhance collaborative reporting chemistry lab practices, being extensible to other types of laboratories.

We can conclude that futures works must provide scalable platforms to ensure widespread access to laboratories through MOOCs. Finally, the use of this medium promotes collaborative learning among students and teachers with characteristics of tolerance, respect, imagination, cooperation.

\section{Acknowledgements}

This research is part of my doctoral thesis in the $\mathrm{PhD}$ program in Systems and Computer Engineering of the National University of San Marcos, Peru. We thank the Superior Polytechnic School of Chimborazo in particular Dr. Galo Insuati for his assistance in conducting laboratory and data collection.

\section{References}

Abrams, N. M. (2012). Combining Cloud Networks and Course Management Systems for Enhanced Analysis in Teaching Laboratories. Journal of Chemical Education, 89, 482-486. http://dx.doi.org/10.1021/ed200160d

Al-Atabi, M., \& Deboer, J. (2014). Teaching Entrepreneurship Using Massive Open Online Course (MOOC). Technovation, 34, 261-264. http://dx.doi.org/10.1016/j.technovation.2014.01.006

Anton, F. D., Anton, S., \& Borangiu, T. (2012). Educational Services in Cloud with IBM Technology: A New Model for Open, on Demand Learning in Higher Education. 2012 International Conference on Information Technology Based Higher Education and Training, Istanbul, 21-23 June 2012, 1-6.

http://www.scopus.com/inward/record.url?eid=2-s2.0-84866612154\&partnerID=40\&md5=afce35a0aadbe01adc5794d893 $\underline{\mathrm{fd} 3206}$

http://dx.doi.org/10.1109/ithet.2012.6246047

Bandi, K. C., Nori, A. K., Choppella, V., \& Kode, S. (2011). A Virtual Laboratory for Teaching Linux on the Web. IEEE International Conference on Technology for Education, Chennai, 14-16 July 2011, 212-215.

http://dx.doi.org/10.1109/T4E.2011.41 
Bhardwaj, S., Jain, L., \& Jain, S. (2010). Cloud Computing: A Study of Infrastructure as a Service (Iaas). International Journal of Engineering, 2, 60-63.

Burd, S. D., Luo, X., \& Seazzu, A. F. (2013). Cloud-Based Virtual Computing Laboratories. Proceedings of the Annual Hawaii International Conference on System Sciences, Wailea, 7-10 January 2013, 5079-5088. http://dx.doi.org/10.1109/HICSS.2013.131

Chine, K. (2010). Learning Math and Statistics on the Cloud, towards an EC2-Based Google Docs-Like Portal for Teaching/ Learning Collaboratively with R and Scilab. Proceedings of 10th IEEE International Conference on Advanced Learning Technologies, Sousse, 5-7 July 2010, 752-753. http://dx.doi.org/10.1109/ICALT.2010.120

Conole, G., \& Unido, R. (2013). Los MOOCs como tecnologías disruptivas: Estrategias para mejorar la experiencia de aprendizaje y la calidad de los MOOCs. Revista de La Educación a Distancia, 16-28.

Cusumano, M. A. (2014). MOOCs Revisited, with Some Policy Suggestions. Communications of the ACM, 57, 24-26. http://dx.doi.org/10.1145/2580941

Daradoumis, T., Bassi, R., Xhafa, F., \& Caballé, S. (2013). A Review on Massive E-Learning (MOOC) Design, Delivery and Assessment. Proceedings of 2013 8th International Conference on P2P, Parallel, Grid, Cloud and Internet Computing, Compiegne, 28-30 October 2013, 208-213. http://dx.doi.org/10.1109/3PGCIC.2013.37

Doelitzscher, F., Sulistio, A., Reich, C., Kuijs, H., \& Wolf, D. (2011). Private Cloud for Collaboration and E-Learning Services: From IaaS to SaaS. Computing, 91, 23-42. http://dx.doi.org/10.1007/s00607-010-0106-z

Fox, G. C. (2013). Collaboration in the Cloud and Online Education Environments. Proceedings of the 2013 International Conference on Collaboration Technologies and Systems (CTS 2013), San Diego, 20-24 May 2013, 2011-2012. http://dx.doi.org/10.1109/cts.2013.6567250

Gajar, P. K., Ghosh, A., \& Rai, S. (2013). Bring You Own Device (BYOD): Security Risks and Mitigating. Journal of Global Research in Computer Science, 4, 62-70.

Hew, K. F., \& Cheung, W. S. (2014). Students' and Instructors' Use of Massive Open Online Courses (MOOCs): Motivations and Challenges. Educational Research Review, 12, 45-58. http://dx.doi.org/10.1016/j.edurev.2014.05.001

Ivica, C., Riley, J. T., \& Shubert, C. (2009). StarHPC—Teaching Parallel Programming within Elastic Compute Cloud. Proceedings of the International Conference on Information Technology Interfaces, Dubrovnik, 22-25 June 2009, 353-356. http://dx.doi.org/10.1109/iti.2009.5196108

Johnson, L., Adams, S., \& Cummins, M. (2012). NMC Horizon Report: 2012 Higher Education Edition. Austin, TX: The New Media Consortium.

Koh, J. H. L., \& Chai, C. S. (2014). Teacher Clusters and Their Perceptions of Technological Pedagogical Content Knowledge (TPACK) Development through ICT Lesson Design. Computers and Education, 70, 222-232. http://dx.doi.org/10.1016/j.compedu.2013.08.017

Li, J., Peng, J., Zhang, W., Han, F., \& Yuan, Q. (2011). A Computer-Supported Collaborative Learning Platform Based on Clouds. Journal of Computational Information Systems, 7, 3811-3818.

http://www.scopus.com/inward/record.url?eid=2-s2.0-80054704344\&partnerID=40\&md5=0ab50db8c9e215bd1a8849dffd 946a0d

Margaryan, A., Bianco, M., \& Littlejohn, A. (2015). Instructional Quality of Massive Open Online Courses (MOOCs). Computers \& Education, 80, 77-83. http://dx.doi.org/10.1016/j.compedu.2014.08.005

Merrill, M. D. (2013). First Principles of Instruction: Identifying and Designing Effective, Efficient, and Engaging Instruction. San Francisco, CA: Pfeiffer.

Mikroyannidis, A., Rizzardini, R. H., Schmitz, H. C., \& Fraunhofer, F. I. T. (2012). A Cloud-Based Approach for Personal and Social Inquiry. Proceedings of the 1st International Workshop on Cloud Education Environments (WCLOUD 2012), Antigua, 15-16 November 2012.

Mircea, M., \& Andreescu, A. (2011). Using Cloud Computing in Higher Education: A Strategy to Improve Agility in the Current Financial Crisis. Communications of the IBIMA, 2011, Article ID: 875547. http://dx.doi.org/10.5171/2011.875547

Moltó, G., \& Caballer, M. (2013). Scalable Software Practice Environments Featuring Automatic Provision and Configuration in the Cloud. Researchgate.Net.

http://www.researchgate.net/publication/259357017_Scalable_Software_Practice_Environments_Featuring_Automatic_Pr ovision_and_Configuration_in_the_Cloud/file/3deec52b2b599d4cef.pdf

Norris, C., \& Soloway, E. (2011). From Banning to BYOD: This Inevitable Shift Is at the Heart of School Change. District Administration, 47, 94

Pedreño, A., Izquierdo, L. M., Ramón, A. B., \& Pernías, P. A. (2013). UniMOOC: Colaborative Work, Innovating in Education. Scientific Journal of Educational Technology, 2, 10-18.

Rajaei, H., \& Aldakheel, E. (2012). Cloud Computing in Computer Science and Engineering Education. American Society for Engineering Education. 
Sayler, A., Grunwald, D., Black, J., \& White, E. (2014). Supporting CS Education via Virtualization and Packages Tools for Successfully Accommodating "Bring-Your-Own-Device” at Scale Categories and Subject Descriptors. Proceedings of the 45th ACM Technical Symposium on Computer Science Education, Atlanta, 5-8 March 2014, 313-318. http://dx.doi.org/10.1145/2538862.2538928

Sinex, S. A., \& Chambers, T. L. (2013). Developing Online Collaboration Skills in the General Chemistry Laboratory. Journal of Chemical Education, 90, 1244-1246. http://dx.doi.org/10.1021/ed300705t

Unesco (2010). Cloud Computing in Education. IITE Policy Brief, (September). http://iite.unesco.org/pics/publications/en/files/3214674.pdf

Vaquero, L. M. (2011). EduCloud: PaaS versus IaaS Cloud Usage for an Advanced Computer Science Course. IEEE Transactions on Education, 54, 590-598. http://dx.doi.org/10.1109/TE.2010.2100097

Woo, S. S., \& Mirkovic, J. (2014). Optimal Application Allocation on Multiple Public Clouds. Computer Networks, 68, 138148. http://dx.doi.org/10.1016/j.comnet.2013.12.001

Xu, L., Huang, D., \& Tsai, W. (2012). V-Lab: A Cloud-Based Virtual Laboratory Platform for Hands-On Networking Courses. Proceedings of the 2012 ACM Conference on Innovation and Technology in Computer Science Education, Haifa, 3-5 July 2012, 256-261. http://dx.doi.org/10.1145/2325296.2325357

Xu, L., Huang, D., \& Tsai, W. T. (2014). Cloud-Based Virtual Laboratory for Network Security Education. IEEE Transactions on Education, 57, 145-150. http://dx.doi.org/10.1109/TE.2013.2282285

Yan, C. (2011). Build a Laboratory Cloud for Computer Network Education. Proceedings of the 6th International Conference on Computer Science and Education, Singapore, 3-5 August 2011, 1013-1018.

http://dx.doi.org/10.1109/iccse.2011.6028808

Yuan, L., \& Powell, S. (2013). MOOCs and Open Education: Implications for Higher Education. 